\title{
Research and Design on Information Service and Management Platform based on Work Integrated Learning Mode
}

\author{
Qi Yuan GAO
}

Information engineering institute, Jilin Engineering Normal University, Jilin, Changchun 130000, China

\begin{abstract}
The work integrated learning mode is the world's more advanced kind of teaching mode, which in many countries have achieved success, but also the rapid development in China. This paper is conscientiously sum of basic school vocational college engineering student management, aimed at the exchange of services and management schools as well as schools, businesses, students communicate among emerging issues were discussed proposed information technology services and management, consciously to promote student learning through the application, to improve learning efficiency, can strong the service awareness of schools, businesses for the students, promote school students and the school's teaching, management form a whole, to facilitate the strengthening of students management and strengthen the contact of schools, businesses, students.
\end{abstract}

\section{Introduction}

Work integrated learning mode in many developed countries has achieved great success. Germany's "dual system", Australia's "new apprenticeships" in Singapore "teaching factory", South Korea's "Industry Cooperation" and other engineering education model combining the development process description, this teaching model can effectively promote economic development. In the information processing, communications technology is developed today, we explore under work-study combination mode information service approach and management tools, the use of Internet technology, wireless communication system to build a platform for students to learn, life service and help strengthen engineering regulatory alternate process, to make them happy to learn and work, to obtain higher efficiency in engineering [1].

\section{Work integrated learning presentation}

"Work Integrated Learning" is "theoretical classroom study and participate in social work posts on a combination of" vocational colleges and enterprises "in practice as the basis for school and comprehensive combination of relevant companies jointly established curriculum models and teaching mode, and students receive training model of paid internships. "Work Integrated Learning" vocational education in the" Industry Cooperation "targeted at the operational level of exploration and practice of the process of the concept of the" lower concept Industry Cooperation "is to implement the approach Industry Cooperation [2]. Engineering combine theoretical knowledge of the learning process and combined with practical work process. Students in vocational schools receive a general cultural knowledge, professional theory and technology education and training at the same time, take advantage of school environment and resources (typically corporate sector) to achieve the combination of work and learning, in order to get work experience, improve the overall quality of all aspects, including the students' professional skills.

\section{Establishment and application of information technology services and management platform}

\subsection{Information services and management platform}

Four elements of engineering are schools, businesses, teachers, students. Engineering projects, these four elements interact and influence each other, establish mechanisms and management information services, combined with the implementation of the teaching mode via engineering, to achieve high-quality culture, skilled personnel [3], llustrates the associated working and learning basic elements is shown in figure 1 .

Corresponding author: gqy1982@126.com 


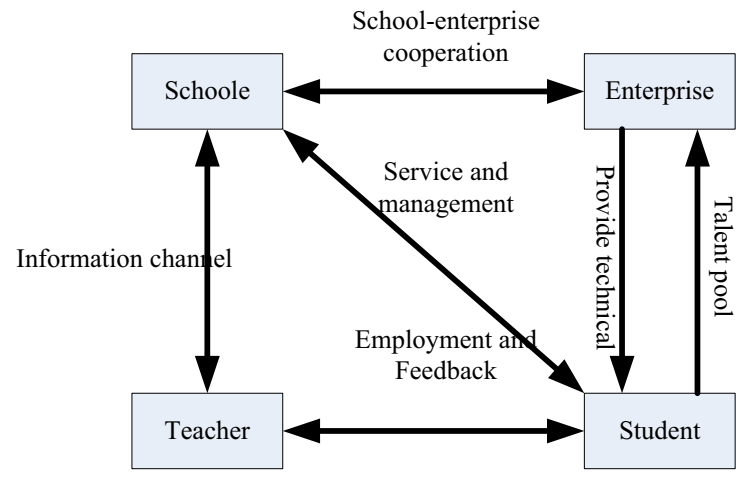

Guidance and feedback

Figure 1.llustrates the associated working and learning basic elements

\subsection{Information technology service management based on work integrated learning mode}

School based on the actual needs, develop promotional video minutes or so, introduce school situation school, professional settings, superior resources and characteristics, the details can browse the school's website.

Through text or video information is to display business basic outlook, corporate culture, technology, and social services ability.

The most important part of resource information and management information services, in the embodiment of the combination of engineering should detail the time, place, people, jobs, operations and engineering skills, objectives and requirements, it is best to be refined to students before departure from mobilization to work and study Bouquet junction each class every day or what the thousands of teachers and students what to do, every time engineering students which targets must be met. Inform the school in advance to these students and businesses, good communication and coordination, strictly in accordance with the proposed plan for promoting the teaching mode of engineering combined [4].

\subsection{Management information platform based on work integrated learning mode}

Management information platform based on work integrated learning mode is shown in figure 2

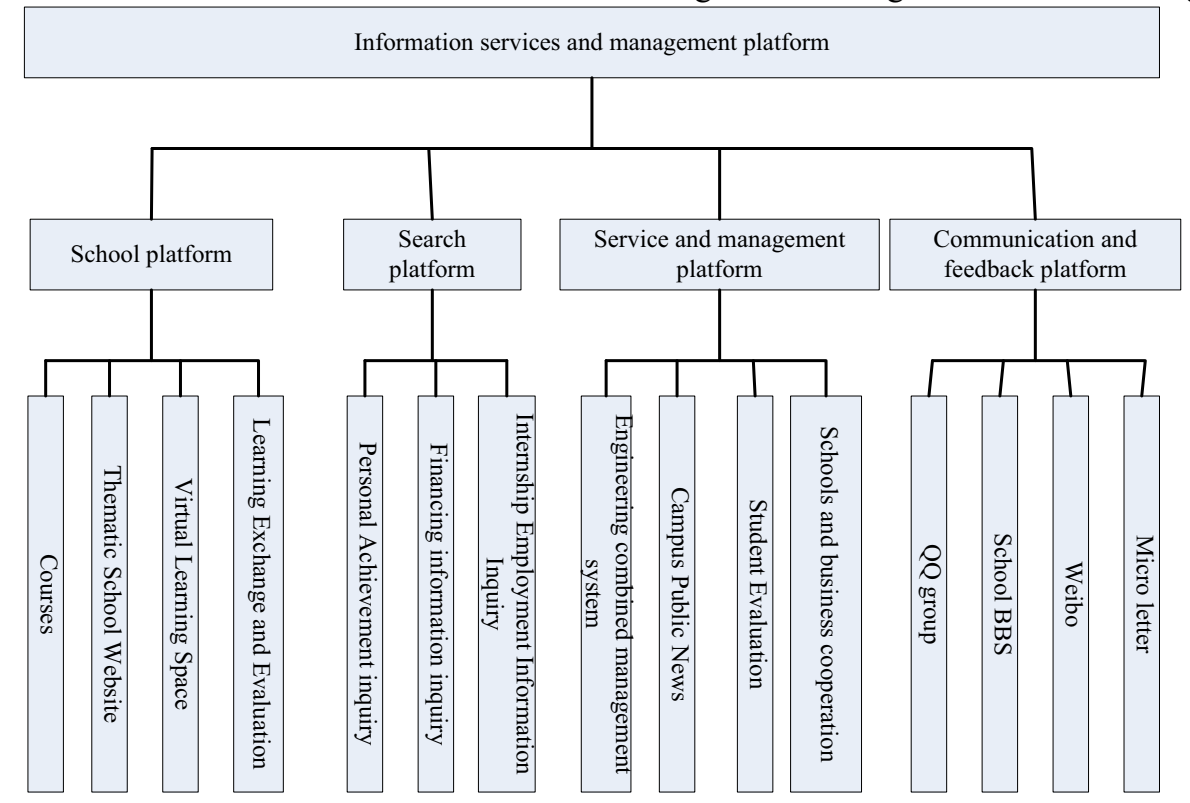

Figure 2.The frame structure and management of information services

\section{Function modules and application of information services and management platform based on working integrated learning mode}

Students in the teaching mode combination of engineering, because the student is not in school, the school of the student services and management barriers of space and time, must be managed and institutionalized means of information in order to eliminate the use of these effects can be obtained so that off-campus students in the same service, so that they consciously complete the learning task. Information services and management platform function module consists of four parts, each module there are specific content management services and support, to be introduced below [5].

\subsection{Learning platform}

Engineering work and learning processes are interwoven, mutually reinforcing process, under the guidance of engineering with the implementation of the program carried out. The main purpose is to promote science engineering work, and from work schools, promote students' skills to master. Establishment of a learning platform is assisted learning for students of engineering in more than, including courses, thematic learning website, virtual learning space, learning communication and evaluation. 
Courses. Schools can combine engineering needs related to the professional development of quality courses and campus instructional video features to add a learning platform, more than students of engineering study according to their need to $\log$ in to complete the online learning platform.

Learning Website. Vocational colleges have their own portal and can easily and docking, which for the construction and application of special learning website provides a basis. By web form creating thematic network courseware, thematic resource library, thematic learning application tools, thematic learning assessment to the combination of engineering students to provide a large number of thematic learning resources and collaborative learning communication tools to make their own choices and determine the research or project design, own collection, analyze and select information, apply knowledge to solve practical problems.

Virtual learning space. On the computer network constructed using multimedia communications technology learning environment that allows teachers and students living in different places were most teaching activities. Classroom through the network, the "teaching" and "learning" environment integrated with the organization of teaching activities, online lectures, online solutions, real-time video-on-demand teaching, real-time video broadcast teaching, virtual classroom teaching monitoring, multimedia lesson planning and teaching, individualized multimedia interactive learning, synchronous tutoring, synchronous test, difficult to resolve, discuss distance learning.

Learning exchanges and evaluation. Most of the students work and study are not very clear effect of learning from the school requires much difference between students, between students and teachers, exchange training instructors and school teachers.

\subsection{Query platform}

Individual query results. Students landing based on personal accounts and passwords school Educational system, query subjects or printed result slips credits circumstances, be aware of learning outcomes. Funding information inquiry. While developing countries, vocational education, the introduction of a number of national student financial aid system, including a variety of ways the National Student Financial Aid scholarships, state grants, government scholarships, motivational scholarships, school scholarships. School funding information will be publicized on a regular basis, the information platform for the students concerned by querying get. internships, employment information inquiry. Employment of students in private practice at the school is very concerned about the employment information released at this stage of internships environment if not satisfied, the individual application, parental consent, after the audit report faculties school career center to reschedule new employment of internships. For the independent careers of students, the unit now dissatisfied with school there are new employment units, you can also apply for school employment recommendation. School faculty instructor authorized to inquire into this department students internships and employment status, be well aware of the whereabouts and status of each student in the school, which greatly facilitates the management of student services.

\subsection{Service and management platform}

During working and learning, authorities schoolenterprise cooperation must be based on the relevant provisions of the necessary checks and supervision, strict examination, and to solve the problem; in order to do a good job assessing students' engineering by academic departments to develop a unified "student of engineering work in conjunction internship training assessment identification Form ", led the teachers, training instructors and business-related personnel jointly responsible for completing the assessment. Conscientiously sum up and exchange on the basis of appraisal of the work of outstanding achievements instructors, students and other concerned personnel to recognize and reward; school regularly held by the enterprise, students and parents representatives to participate in work and study experience exchange and summary We will exchange information and further promote cooperation between university and efficacy results of its work.

\subsection{Communication and feedback platform}

Each student has a number of teachers in the future to create engineering services group, requires that each student must be added to this group. Teachers or students can make an announcement by the group of functions, informing, various exchanges, data or file transfer. On the one hand provide for student learning life services and help the other hand, teachers and students can learn the latest information available to the other person, through point to point, point opposite the face information exchange points, to reach the student management purposes, Even if students are not online, when students have time landing can also receive the information sent by the teacher or other students, very convenient to use.

Campus BBS- like just for the university's students to build self-management by the student network system for student speech to provide information platform. Typically used to publish news, notice or announcement, also often used as chatting purposes. With the rapid development of university networks, it has become an important part of campus culture indispensable.

Micro blogging is a relationship based on user information sharing, dissemination and access platform, users can, as well as various individual components of the client community, word about text updates, and instant sharing.

AC micro message appears between people has even reached the point where more convenient. Between students and teachers can communicate with each other through the micro timely letter, to share their experiences with each other and the joy of success. 


\section{Information services and management practices based on working integrated learning}

\subsection{Factors Affecting information services and management}

Combination of engineering management students, the school has a good plan for a student to leave the school, it is very difficult to implement. The use of information way for students to provide services and management, information platform builders professionalism, student consciousness and initiative put forward a very high demand.

One student factors, information services and implementation of management functions must be based on the premise of the system, so that students take the initiative to access to services and management platform for information browsing and communication, and has put forward various problems that exist in project engineering, are fed back to the instructors, schools, businesses, parties must promptly solve student problems reflected. Information services and requires students to actively manage the problems, difficulties, ideas through the platform to inform schools, school students through the coordination of the issues of concern solved, there is no reason students do not learn.

Second, the teacher factor, information services and management process, the teacher's role is to guide, managers, service providers. Before engineering, teachers need to spend a lot of time and detailed understanding of each student's basic information, work also responsible for student attendance, counseling, ideological and political education, performance assessment and evaluation of students' daily transaction processing and other work.

Three part-time technical factors counseling staff, part-time technical school counselors hired in engineering process of the students and on-site training guidance counseling, student mastery of skills primarily by their assessment and evaluation.

\subsection{Role of Information Technology Services and Management}

Students are the main target of school work, information technology services and management is based on the purpose of educating people at the school to take a modern way of working. Especially for students to work and study, they themselves not in school, the school has duty-bound to provide necessary assistance for their learning process, working process, the process of life, but also the use of school rules to constrain their behavior, we must implement them information technology services and management. On the one hand extended school services and management functions. Combined engineering is an important part of higher vocational teaching institutions, in this part of providing good service and management for students, to help them acquire practical skills, the successful completion of their studies. Information services and management in the benign effects of people, goods, mechanisms will form school-enterprise conspiracy, both inside and outside, allround, multi-level service pattern.

\subsection{Significance and Management Information Services}

Reflect student learning initiative and efficiency. Information services and management using the restraint system and incentives to promote student initiative to acquire resource information and assistance through the platform, to keep their own learning conditions and teachers, parents, students evaluate their own learning, so that the learning process, stage learning outcomes idea.

It reflects the teaching of information management and systematic. All engineering data were transmitted, communication, storage through information technology platform. Teaching, the students do, what needs to reach a daily target requirements; instructor how to do it, to observe the state of student learning every day and do a good job guidance and records, combining learning with working embodiments are clearly defined.

Learning Assessment reflect institutionalized and impartiality of. Learning evaluation mechanisms and management of information services is the evaluation stage, after the end of a learning unit, automatically generated by the system based on feedback from objective data. After all the school units completed form summative evaluation.

\section{Conclusions}

Implementation of information services and management, teaching students to vocational colleges of engineering, management, service can play a certain role. In future studies, as the school-enterprise cooperation and workstudy combination to change the teaching mode, schools, businesses and services to students and management will also change accordingly, management platform for application modules will be more refined, in order to truly improve teaching and management efficiency.

\section{References}

1. Zh.Q.Zhao. Understanding of some basic concepts combining engineering courses, China Vocational and Technical Education (2008).

2. J.Zhu, Z.G.Wang. Curriculum Reform and Practice of Engineering combined mode study,Vocational Technical Institute . (2009).

3. L.ZH. Li. Engineering Practice binding mode, in vocational students vocational skills training, Sichuan Normal University . (2010).

4. T.Cheng. Vocational Campus Culture Construction Engineering Research binding mode,Hunan University . (2011).

5. J.Y.Qiu. Work-study Combination Mode Vocational School Ideological and Political Education Research ,Huaqiao University . (2014). 